Published in final edited form as:

Xiao, K., Chen, L., Jiang, L., \& Antonietti, M. (2020). Carbon nitride nanotube for ion transport based photo-rechargeable electric energy storage. Nano Energy, 67: 104230.

doi:10.1016/j.nanoen.2019.104230.

\title{
Carbon nitride nanotube for ion transport based photo-rechargeable electric energy storage
}

Kai Xiao, Lu Chen, Lei Jiang and Markus Antonietti

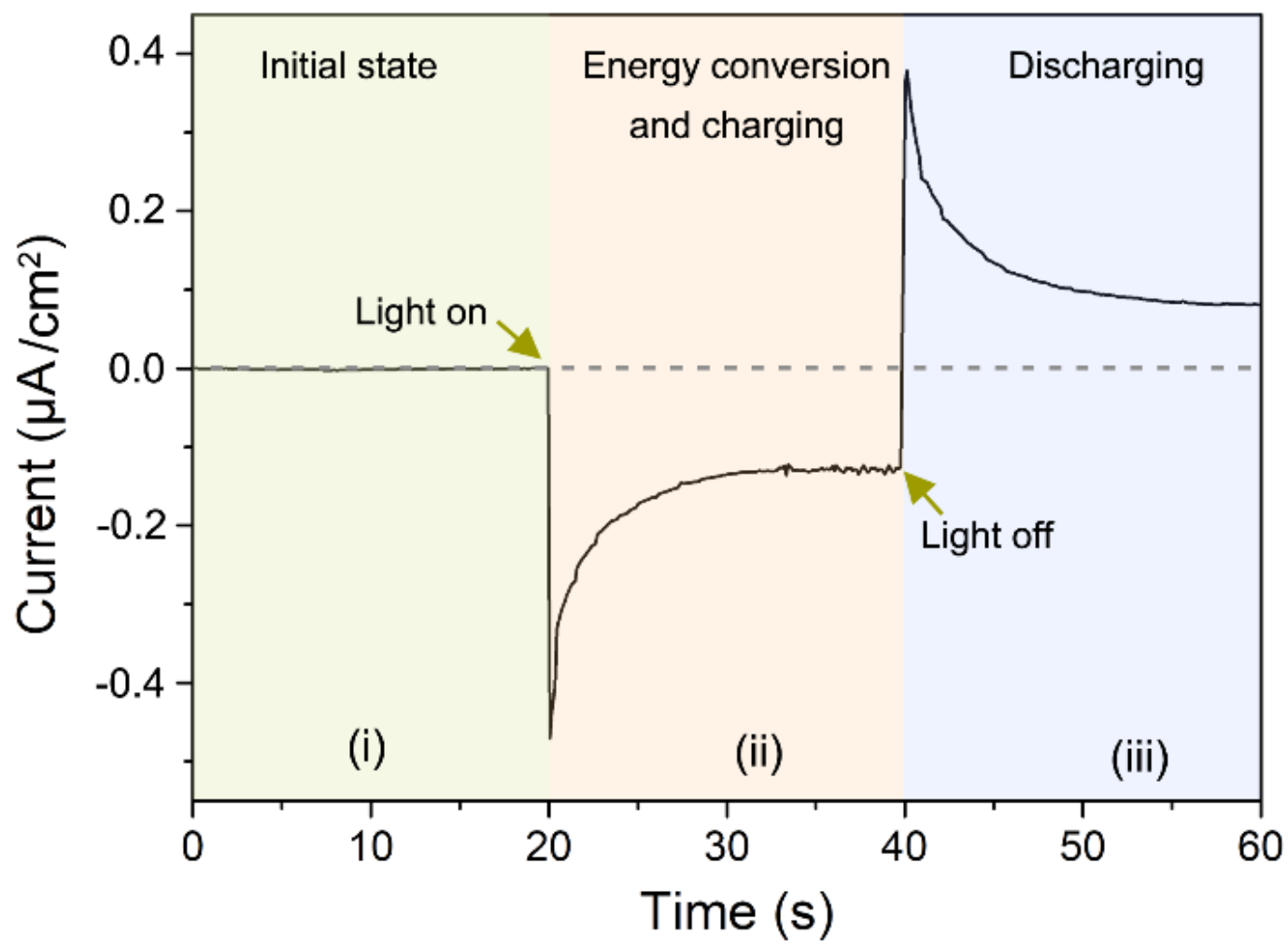

A photo-rechargeable electric energy storage system is designed by fabricating carbon nitride nanotube membrane, which can harvest solar energy and then store it as ionic power. The charging and discharging ionic current and voltage can be further scaled up by simply through series and parallel connections of multiple. 
Carbon nitride nanotube for ion transport based photo-rechargeable electric energy storage

Kai Xiao*, Lu Chen, Lei Jiang and Markus Antonietti

Dr. L. Chen, Prof. Dr. Markus Antonietti, Dr. K. Xiao

Max Planck Institute of Colloids and Interfaces, Department of Colloid Chemistry, 14476

Potsdam, Germany.

E-mail: xiaokai@iccas.ac.cn

Dr. L. Chen, Prof. L. Jiang

Key Laboratory of Bio-inspired Smart Interfacial Science and Technology of Ministry of Education, School of Chemistry, Beihang University, 100191 Beijing, P.R. China.

Keywords: (Nanofluidic, Ions transport, Carbon nitride, Solar energy, Photo-rechargeable)

\begin{abstract}
To resolve the fluctuation and storage issues renewable energy is facing, photorechargeable electric energy storage systems may contribute by immediately storing the generated electricity locally. Complementing the various conventional chemical-reactionbased photo-rechargeable electric energy storage systems, we propose here a physical ion transport-based photo-rechargeable electric energy storage system to harvest solar energy and then store it in place as ionic power, which can be reconverted into electric energy later but momentarily. The new solar energy conversion and storage approach is based on a carbon nitride nanotube membrane, which can be fabricated by chemical vapor deposition method. The charging and discharging current peaks can reach to $1.8 \mu \mathrm{A} / \mathrm{cm}^{2}$, which can be scaled up through parallel (current) and series (voltage) connections. Our findings provide possibilities in advancing the design principles for a combined, easy and efficient solar energy conversion and storage system.
\end{abstract}




\section{Introduction}

The global energy demand is increasing at the same time as fossil fuel resources are dwindling. ${ }^{1,2}$ Solar energy is one of the most promising, effective and emission-free energy sources to meet the energy demands we are facing now. ${ }^{3}$ However, the energy has to be stored to compensate the fluctuating availability of the sun and the actual energy demand. To circumvent the fluctuation and storage issues renewables are facing, photo-rechargeable electric energy storage systems may solve this problem by intermediate storage of the generated electricity. ${ }^{4}$ Different possibilities for storing large amounts of energy are proposed. Generally speaking, two different strategies were put forward to realize the photorechargeable electric energy storage process: one is external combination of photovoltaic cells and energy storage systems, e.g. lithium ion batteries, ${ }^{5,6}$ redox flow batteries, ${ }^{7}$ as well as electrochemical supercapacitors; ${ }^{8}$ another one is the internal integration of photoelectrodes with rechargeable batteries. ${ }^{9-11}$

Although most of the generated photovoltaic energy is still stored by external batteries (e.g., $\mathrm{Li}$ ion or nickel/metal hydride batteries), there is still potential to improve its energy generation and storage efficiency because the relatively long distance between both parts will lower the energy storage efficiency. ${ }^{12,13}$ The integrated photoelectrode/battery device is simpler, and the solar energy is locally stored where it is produced. ${ }^{5,14}$ Nevertheless, this requires the seamless combination of the elementary steps of light harvesting, charge carrier separation, and their storage to retrieve electrical energy on demand. ${ }^{15}, 16$ To avoid shortcomings, a physical process rather a chemical process is much easier to adapt, e.g. solar energy can be harvested and then stored as ionic power, which can be converted into electric energy momentarily.

Ions transport and separation in electrolyte provide this new approach to realize the aim. ${ }^{17}$,

${ }^{18}$ Ions transport including ion selectivity, rectification and pumping is regarded as a basic tool of living cells. ${ }^{19}$ In the view of applied research, ion transport is also relevant with salinity gradient energy conversion, ${ }^{20}$ water desalination ${ }^{21}$, and ionic sensory system by ion selective channels or membranes. ${ }^{22}$ Herein, we analyze the possibilities of an ion transport based photorechargeable electric energy storage system, all in one single polymeric carbon nitride membrane. In general, carbon nitride and its derived materials can be used directly as photoelectrode for photoelectrochemical application, ${ }^{23-26}$ while cannot store the energy generated as it is. This photo-rechargeable electric energy storage system will provide a 

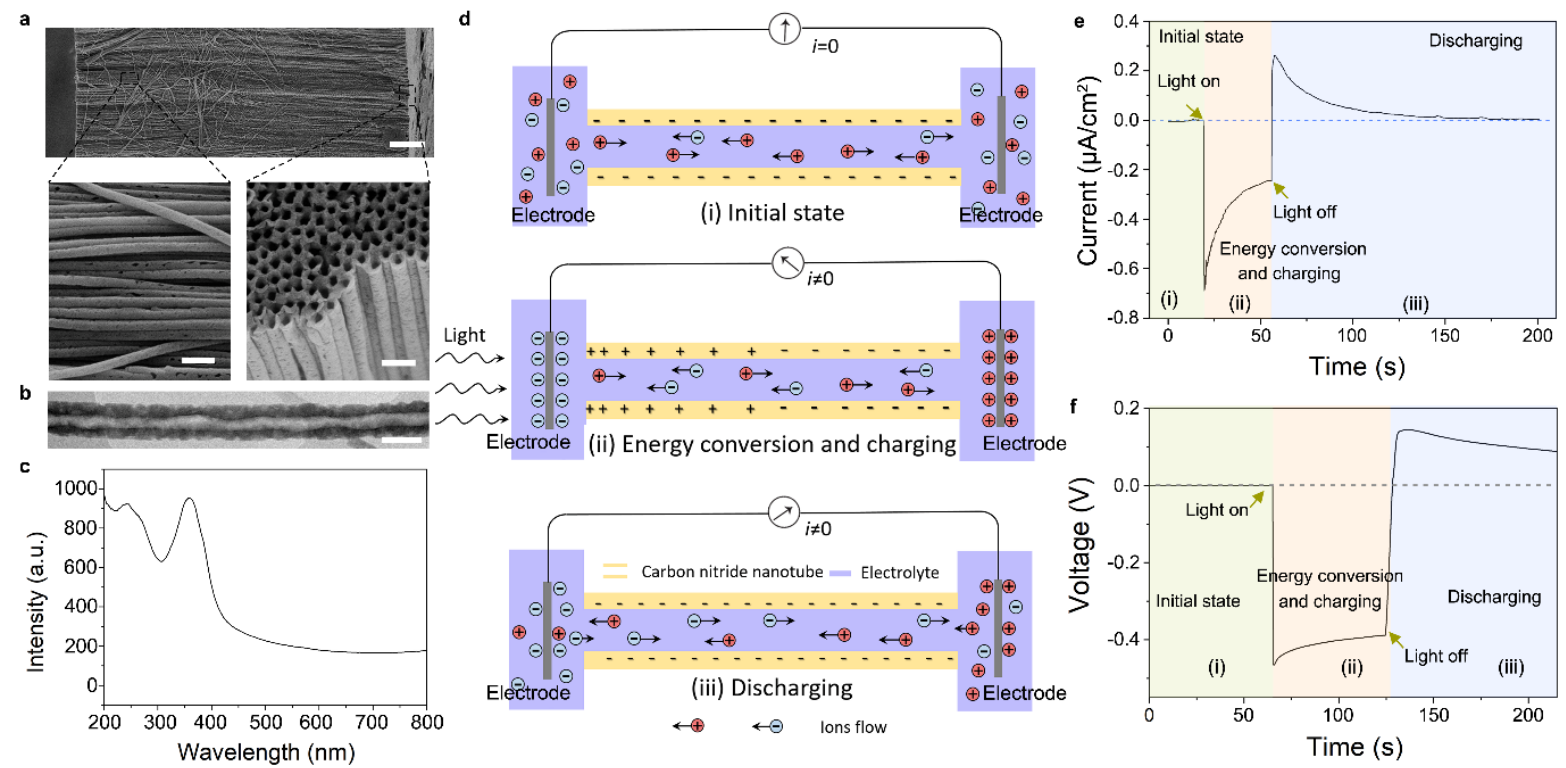

Figure 1. Morphology and schematic configuration of a nanotube membrane based photo-rechargeable electric energy storage system. a, SEM images of CNNM, scale bar 5 $\mu \mathrm{m}$ (upper) and $200 \mathrm{~nm}$ (under). b. TEM image of the section of signal $\mathrm{C}_{3} \mathrm{~N}_{4}$ nanotube, scale bar $100 \mathrm{~nm}$. c, UV-Vis absorption spectroscopy of CNNM. d, Schematic representation of the setup and the working mechanism of the photo-rechargeable electric energy storage system: (i) Initial state, without ionic current; (ii) Charging process by light irradiation; (iii) Discharging process after removing light irradiation. e, Typical current-time curve in initial, charging and discharging processes. f, Typical voltage-time curve in initial, charging and discharging processes. 
possibility to overcome the intermittency of solar radiation by the flexible light-induced electrical energy storage and release on demand by a one-component light-charged battery.

\section{Result and Discussion}

The carbon nitride nanotube membrane (CNNM) used in this work is fabricated based on our previous work, ${ }^{27,28}$ and has a thickness about $60 \mu \mathrm{m}$ and an area about $0.2 \mathrm{~cm}^{2}$, with an external pore diameter of $100 \mathrm{~nm}$, internal pore diameter of $50 \mathrm{~nm}$ (Figure 1a, 1b and Figure S1). The UV-Vis absorption spectra of CNNM is consistent with typical carbon nitride powders, ${ }^{29}$ and indicates its usefulness as an optical transducer (Figure 1c and Figure S2). The ions transport based solar energy conversion and storage properties were measured in a home-made H-type cell (Figure S3), which was filled with $\mathrm{KCl}$ electrolyte solution as ion transport medium and used commercial porous carbon electrode as the working electrode for simplicity (Figure 1d).

In initial state, cation $\left(\mathrm{K}^{+}\right)$-dominated ion transport across the negative charged nanotube occurs freely and symmetrically, without ionic current at the macroscopic level (Figure 1d i). With unilateral light irradiation, light induced charge carriers separation will change the surface charge distribution in the carbon nitride nanotube, from symmetric negative charge to an asymmetric charge pattern, which then drives ions (cation and anion) separation and transport in electrolyte to balance the inhomogeneous surface charge distribution. ${ }^{18}$ In this condition, the cations $\left(\mathrm{K}^{+}\right)$move to the negative charged area while anions $\left(\mathrm{Cl}^{-}\right)$move to the positive charged area, and both of them accumulate and store in the porous carbon electrode to substantiate the charging process, as in a capacitor (Figure 1d ii and Figure S4, S5) ${ }^{30}$ In the charging process, the diffusive countercurrent is also generated and increases gradually along with illumination time because of the ion concentration difference in two sides, which results in a gradually decreasing charging ionic current and voltage. After removing light, carbon nitride nanochannel surface tuned back to its initial homogeneous surface charge property, and ions (cation and anion) also move back to their initial place to accomplish the discharging process (Figure 1d iii), then a cycle of charging and discharging is finished. Figure 1e showed the ionic current-time curve in these three different states with 320 $\mathrm{mW} / \mathrm{cm}^{2}$ blue light irradiation. Ionic current in initial state was almost zero while it increased sharply to $-0.7 \mu \mathrm{A} / \mathrm{cm}^{2}$ after turning the light on and decreased gradually because of the diffusive countercurrent. ${ }^{31}$ After tuning off light, the negative charging current tuned into positive discharging current (about $0.3 \mu \mathrm{A} / \mathrm{cm}^{2}$ ) peak and decreased gradually as discharge goes on. Similar trend is also seen for the charging and discharging potential, with $-0.46 \mathrm{~V}$ 

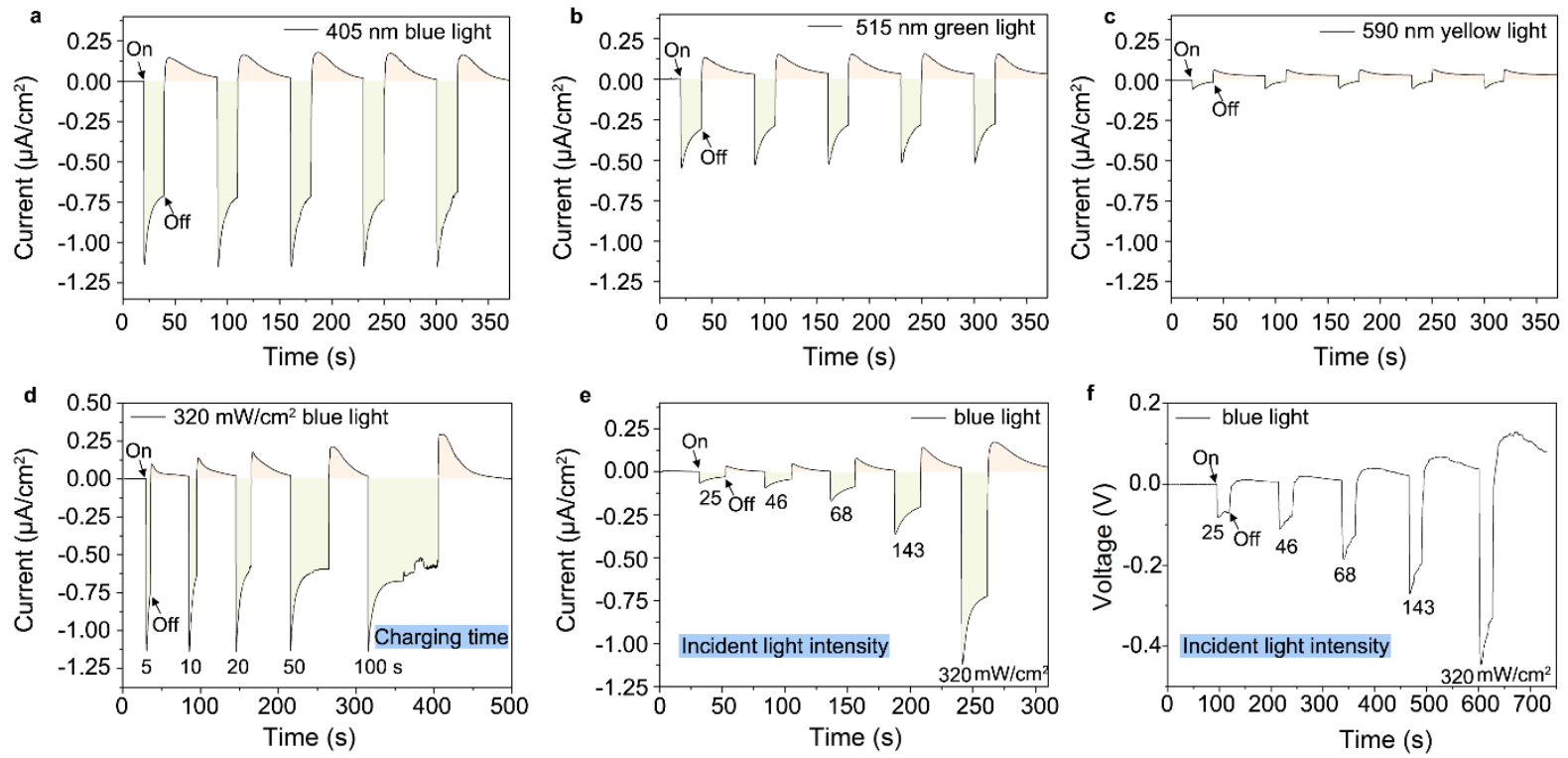

Figure 2. Dependence of ionic current on light energy, charging time, and light intensity. a-c, Current-time curves as a function of light energy (a: $405 \mathrm{~nm}$ blue light; b: $515 \mathrm{~nm}$ green light; c: $590 \mathrm{~nm}$ yellow light). d, Current-time curve as a function of charging time (illuminated time: 5, 10, 20, 50, and $100 \mathrm{~s}$ ). e, Current-time curve as a function of incident light intensity $\left(25,46,68,143\right.$, and $\left.320 \mathrm{~mW} / \mathrm{cm}^{2}\right)$. f, Voltage-time curve as a function of incident light intensity $\left(25,46,68,143\right.$, and $\left.320 \mathrm{~mW} / \mathrm{cm}^{2}\right)$. 
charging and $0.15 \mathrm{~V}$ discharging potential (Figure 1f), the small discharging voltage can be ascribed to the impedance of electrolytes. ${ }^{32,} 33$ In addition, the charging current and voltage peaks are not equivalent with discharging current and voltage peaks because discharging is a diffusive process on longer length scales of the ionic capacitance.

Light energy is crucial to influence the charging and discharging properties. As shown in Figure 2a-c, charging and discharging currents were collected in $0.01 \mathrm{M} \mathrm{KCl}$ electrolyte with $20 \mathrm{~s}$ charging time and $50 \mathrm{~s}$ discharging time. $320 \mathrm{~mW} / \mathrm{cm}^{2}$ blue light produced a charging peak current of $1.15 \mu \mathrm{A} / \mathrm{cm}^{2}$ and a discharging peak current of $0.15 \mu \mathrm{A} / \mathrm{cm}^{2}$ (Figure 2a), while the charging peak current and discharging peak current under green light were 0.52 $\mu \mathrm{A} / \mathrm{cm}^{2}$ and $0.12 \mu \mathrm{A} / \mathrm{cm}^{2}$, respectively (Figure $\mathbf{2 b}$ ). In yellow light with same incident intensity, both the charging peak current and discharging peak current are negligible, only $0.05 \mu \mathrm{A} / \mathrm{cm}^{2}$ and $0.04 \mu \mathrm{A} / \mathrm{cm}^{2}$ (Figure 2c). The results are consistent with the light absorption of carbon nitride nanotube membrane (Figure 1c).

Charging time is another crucial factor to influence the solar energy conversion and storage. As shown in Figure 2d, current-time curve illustrated charging and discharging peaks with various charging time of $5 \mathrm{~s}, 10 \mathrm{~s}, 20 \mathrm{~s}, 50 \mathrm{~s}$, and $100 \mathrm{~s}$, respectively. The charging peaks value have no obvious difference with each other because they are only associated with the incident light energy and intensity, while the discharging peaks gradually increased from 0.09 $\mu \mathrm{A} / \mathrm{cm}^{2}$ under $5 \mathrm{~s}$ charging time to $0.31 \mu \mathrm{A} / \mathrm{cm}^{2}$ under $100 \mathrm{~s}$ charging time. It's obvious that the increase in discharging peak (energy storage capacity) is due to the increased ion capacity stored in the porous carbon electrodes with longer charging time. Incident light intensity significantly influenced both the charging and discharging peak. With the increase of blue light intensity from $25 \mathrm{~mW} / \mathrm{cm}^{2}$ to $320 \mathrm{~mW} / \mathrm{cm}^{2}$, both the charging current peak and discharging current peak increased obviously, from 0.065 to $1.15 \mu \mathrm{A} / \mathrm{cm}^{2}$ for charging process and 0.03 to $0.11 \mu \mathrm{A} / \mathrm{cm}^{2}$ for discharging process (Figure 2e). The same tendency goes for charging and discharging ionic potential (Figure 2f) and the system exhibited stable cycle performance (Figure S6).

Choice of the electrolyte obviously has to affect the charging/discharging processes. ${ }^{34}$ To the $1 \mathrm{M}$ electrolyte, both charging and discharging current peaks are high, but decrease sharply with time, while the charging and discharging current peaks at low concentrations of $0.0001 \mathrm{M}$ are low, but decreased modest along with time (Figure 3a-e). Both the charging and discharging current peaks show a clear concentration dependence, plotted in Figure 3f. For the concentration from $1 \mathrm{M}$ to $0.0001 \mathrm{M}$, charging current density peaks were -1.8 

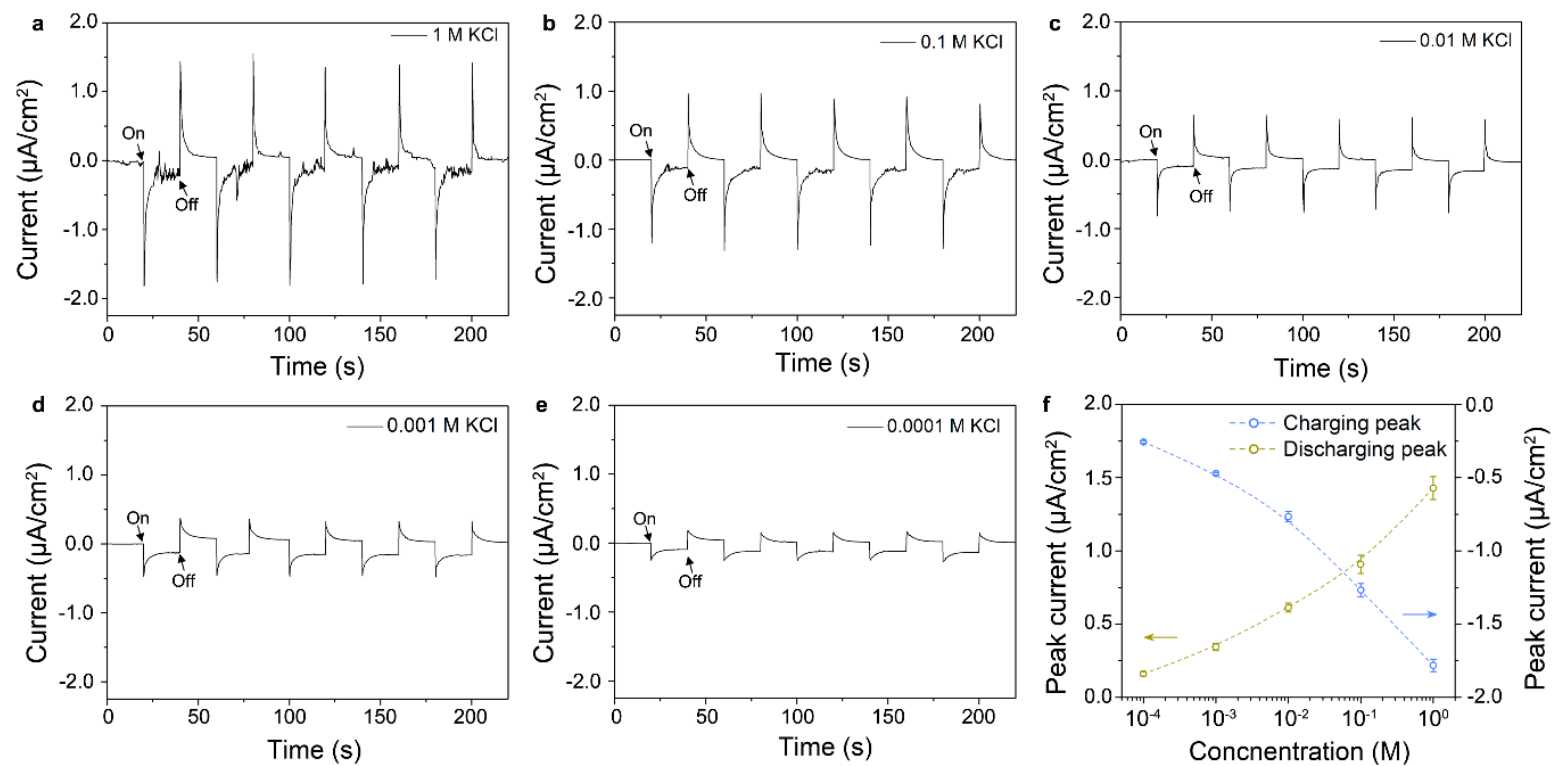

Figure 3. Dependence of ionic current on electrolyte concentration. a-e, The peak currents both in charging and discharging process decrease gradually with the decreasing of electrolyte concentration (from $1 \mathrm{M}$ to $0.0001 \mathrm{M}$ ), which showed a linear trend (f). 
$\mu \mathrm{A} / \mathrm{cm}^{2},-1.29 \mu \mathrm{A} / \mathrm{cm}^{2},-0.77 \mu \mathrm{A} / \mathrm{cm}^{2},-0.52 \mu \mathrm{A} / \mathrm{cm}^{2}$, and $-0.25 \mu \mathrm{A} / \mathrm{cm}^{2}$ receptively, while discharging current peaks were $1.49 \mu \mathrm{A} / \mathrm{cm}^{2}, 0.91 \mu \mathrm{A} / \mathrm{cm}^{2}, 0.62 \mu \mathrm{A} / \mathrm{cm}^{2}, 0.30 \mu \mathrm{A} / \mathrm{cm}^{2}$, and $0.18 \mu \mathrm{A} / \mathrm{cm}^{2}$ receptively. Diffusive leakage should be responsible for the smaller discharging current peaks compared with charging current peaks, while the small current in low concentration can be attributed to shielding effect of electrical double layer, the length of which is inversely proportional to the electrolyte concentration. ${ }^{35,36}$ To high concentration electrolyte, a large amount of ions move to generate electrical double layer around porous carbon electrodes instantaneously, resulted in large instantaneous ionic current; to the low concentration electrolyte, sparse ions need more time to generate electrical double layer to balance the photo-induced potential across nanotube. In addition to this, size of ions can also affect the charging and discharging ionic current peaks (Figure S7). Smaller ions have a faster migration rate, then sharper charging and discharging peaks.

More importantly, the charging and discharging current and voltage can be further scaled up by simple series and parallel connections of multiple devices. Figure $4 \mathbf{a}$ depicted the schematic parallel connection of sample 1 and 2 by wires. For individual sample 1, the peak charging and discharging currents are $0.5 \mu \mathrm{A} / \mathrm{cm}^{2}$ and $0.2 \mu \mathrm{A} / \mathrm{cm}^{2}$, respectively; for individual sample 2, the peak charging and discharging currents are $0.75 \mu \mathrm{A} / \mathrm{cm}^{2}$ and $0.23 \mu \mathrm{A} / \mathrm{cm}^{2}$, respectively. For the parallel connection of them, the peak charging and discharging currents are enlarged to $1.28 \mu \mathrm{A} / \mathrm{cm}^{2}$ and $0.52 \mu \mathrm{A} / \mathrm{cm}^{2}$, respectively (Figure $4 \mathbf{b}$ ). Figure $4 \mathbf{c}$ depicted the schematic series connection of sample 1 and 2 by wires. For individual sample 1, the peak charging and discharging voltages are $0.18 \mathrm{~V}$ and $0.05 \mathrm{~V}$, respectively; for individual sample 2 , the peak charging and discharging voltages are $0.18 \mathrm{~V}$ and $0.04 \mathrm{~V}$, respectively. For the parallel connection of them, the peak charging and discharging voltages are enlarged to $0.4 \mathrm{~V}$ and $0.09 \mathrm{~V}$, respectively (Figure $\mathbf{4 b}$ ). This extendable property provides a possibility for real technical devices. ${ }^{37,38}$

However, we also should never forget that the generated and stored "ionic energy" here is rather "diluted": the incident photon-to-electron conversion efficiency for this photorechargeable electric energy storage system is calculated as about $0.03 \%$; the average charging and discharging efficiency is calculated about $73.45 \%$. We have to admit that the operating voltage, the conversion efficiency and the coulombic efficiency of this single cell is low compared with other photo-rechargeable electric energy storage systems. ${ }^{39,40}$ This is the disadvantages of all "ionic energy" systems because of slow ion transport speed, including salinity gradient energy and other ion pump energy systems. ${ }^{41,}{ }^{42}$ In current stage, this "ionic 

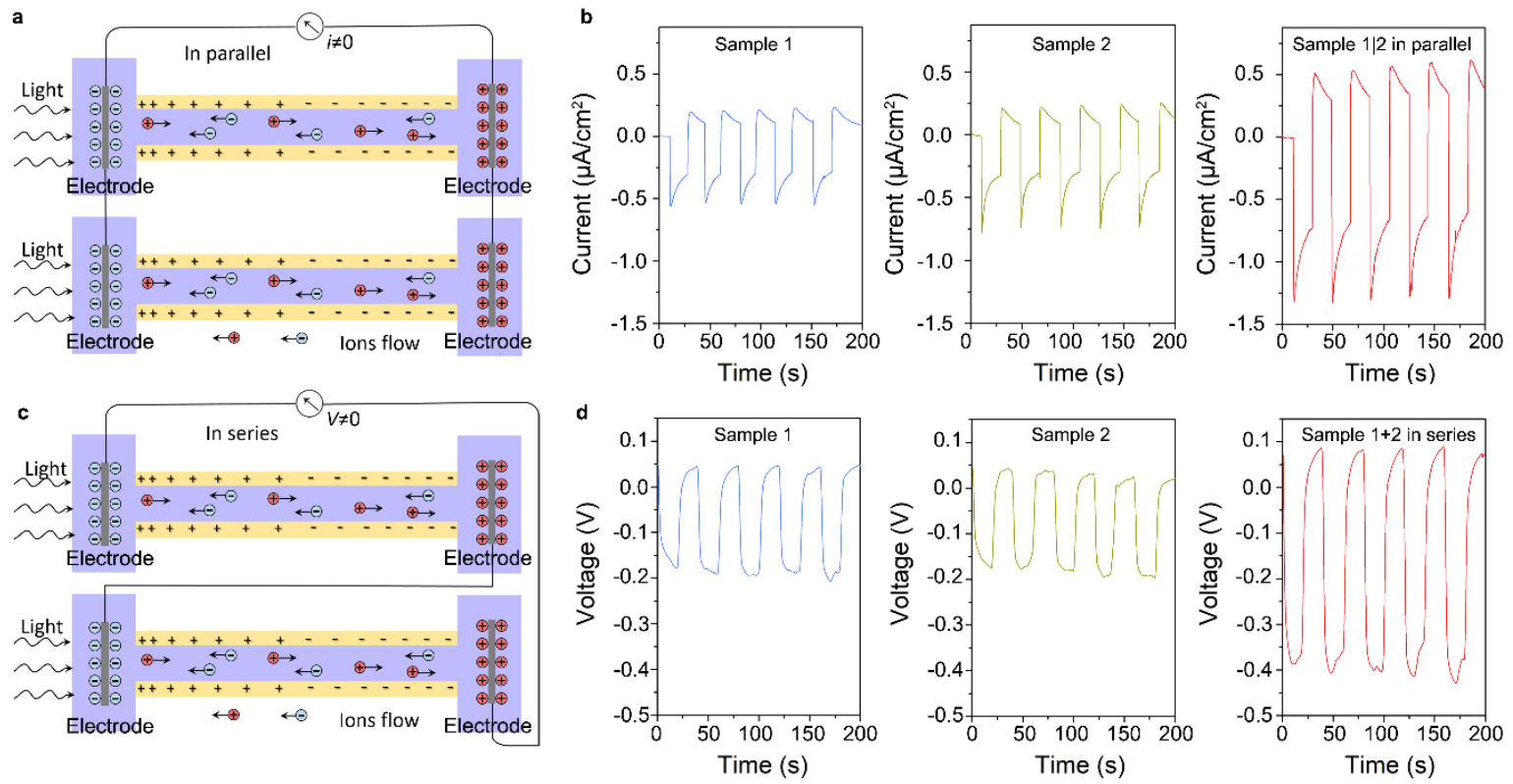

Figure 4. Scalability of the harvesting electricity. a. Schematic representation of parallel connection of the two samples, which can scale up the short circuit current (1|2). b, Short circuit currents of sample 1, sample 2, and parallel connection 1|2. c, Schematic representation of series connection of the two samples, which can scale up the open-circuit voltage $(1+2)$. d, Open-circuit voltages of sample 1 , sample 2 , and series connection $1+2$. 
energy" generation and storage system is indeed far from practical applications, while we should have hopes for this because there are new scientific tools and approaches to improve that, for example, combing this photo-rechargeable system with salinity gradient system. ${ }^{43}$

As shown in Figure 5a, a concentration gradient of $10 \mathrm{mM} / 0.1 \mathrm{mM} \mathrm{KCl}$ electrolyte is applied between the two compartments. When there is only salinity gradient (Figure 5a i), the osmotic current (the current at zero potential) and the osmotic potential (the potential needed to zero the current) can be determined, and the effect is due to the ion selectivity of CNNM (Figure S8). After unilateral light irradiation at high concentration (Figure 5a ii), both the osmotic current and potential are expected to be enhanced because of the redistribution of surface charge in CNNM. Figure 5b shows the current-voltage ( $I-V)$ curves at a concentration gradient of 100 ( $\mathrm{C}_{\text {high }}: 10 \mathrm{mM}$; $\left.\mathrm{C}_{\text {low }}: 0.1 \mathrm{mM}\right)$ using different laser intensities, from which the osmotic current (I Ismotic) and the osmotic potential ( $\mathrm{V}_{\text {Osmotic }}$ ) can be read out. Before blue light irradiation $\left(0 \mathrm{~mW} / \mathrm{cm}^{2}\right)$, IOsmotic is $0.4 \mu \mathrm{A} / \mathrm{cm}^{2}$ and $\mathrm{V}_{\text {Osmotic }}$ is $0.32 \mathrm{~V}$. After light irradiation, IOsmotic increases to $1.05 \mu \mathrm{A} / \mathrm{cm}^{2}$ and $2.8 \mu \mathrm{A} / \mathrm{cm}^{2}$, and $\mathrm{V}_{\text {Osmotic }}$ increases to $0.42 \mathrm{~V}$ and $0.59 \mathrm{~V}$ under $110 \mathrm{~mW} / \mathrm{cm}^{2}$ and $380 \mathrm{~mW} / \mathrm{cm}^{2}$, respectively. Light wavelength also plays a crucial factor to enhance the integrated energy conversion power density (Figure 5c). To different light wavelengths with $380 \mathrm{~mW} / \mathrm{cm}^{2}$, I Osmotic increases from $0.4 \mu \mathrm{A} / \mathrm{cm}^{2}$ to $0.95 \mu \mathrm{A} / \mathrm{cm}^{2}(595$ $\mathrm{nm}$ Yellow light), $1.6 \mu \mathrm{A} / \mathrm{cm}^{2}$ (515 nm Green light), and $2.8 \mu \mathrm{A} / \mathrm{cm}^{2}$ (405 nm Blue light),

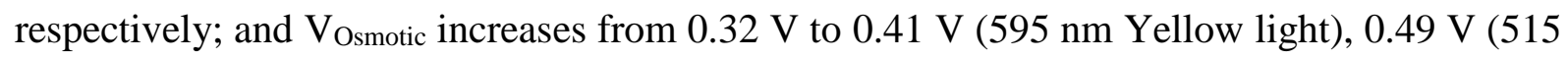
$\mathrm{nm}$ Green light), and 0.59 V (405 nm Blue light), respectively. The enhancement in osmotic current and osmotic potential can be ascribed to the light-induced surface charge distribution along carbon nitride nanotube, and therefore enhanced ion selectivity. ${ }^{44,45}$

\section{Conclusions}

In summary, a model, ion transport based photo-rechargeable electric energy storage system was realized via carbon nitride nanotube membrane. Light induced charge carrier separation which then drive ions transport in electrolyte and accumulation near electrodes is regarded as the base of working principle of photo-rechargeable electric energy storage system. The carbon nitride nanotube membrane integrates the functions of light absorption and ion transport, resulting in a simple and efficient solar energy conversion and storage system. Beyond that, the charging and discharging current and voltage can be further scaled up by simple series and parallel connections of multiple devices to realize large-scale industrial applications, or integrating salinity gradient energy generation to enhance energy conversion efficiency and density. In comparison with other chemical reaction-based photo- 


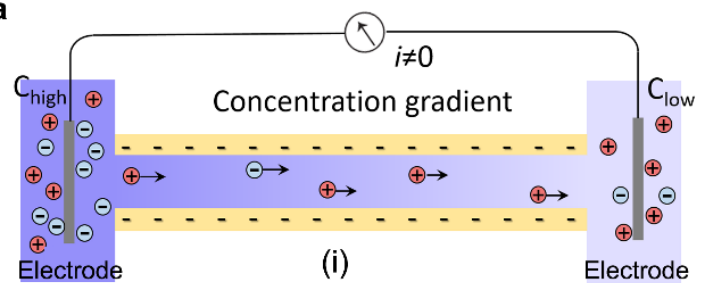

b

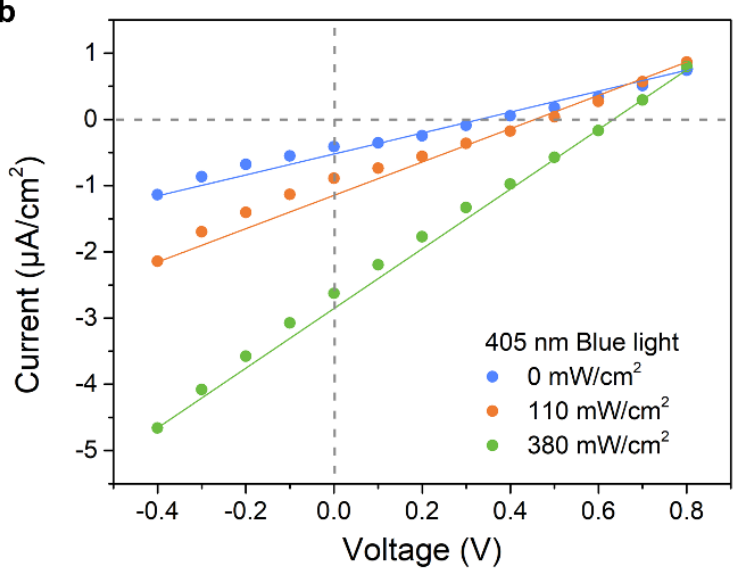

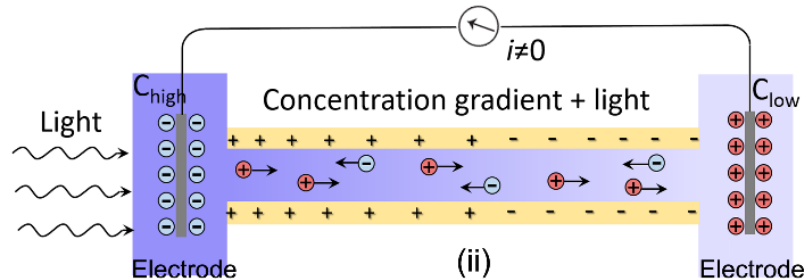

(ii)

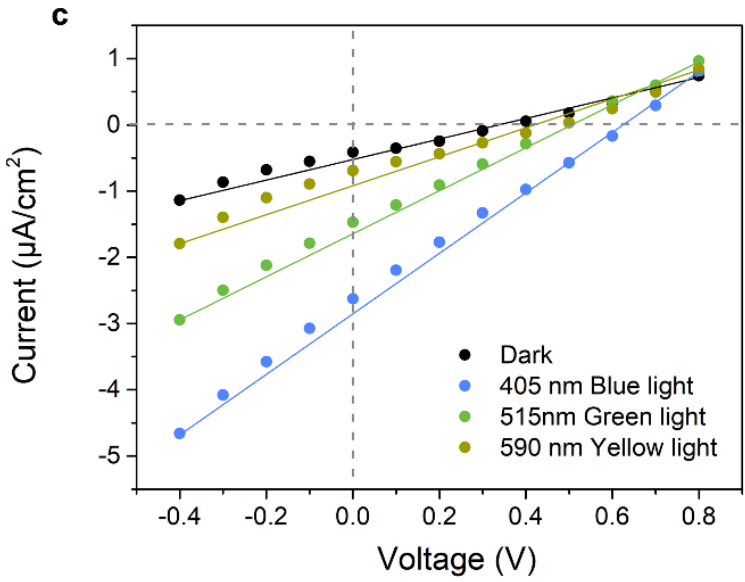

Figure 5. Integrating solar energy and salinity gradient energy harvesting based on CNNM. a. Schematic representation of salinity gradient energy conversion and light enhanced salinity gradient energy conversion based on CNNM. b, I-V characteristics at a concentration gradient of 100 using different blue light intensities. c, I-V characteristics at a concentration gradient of 100 using different laser wavelengths. 
rechargeable electric energy storage systems, the physical ions transport-based system is cheap, easy to fabricate, and extendable.

\section{Acknowledgments}

We acknowledge the support of the technicians in MPIKG. We acknowledge the help from Dr.

T. Heil for TEM support. K.X. acknowledges the support of Alexander von Humboldt Foundation. This work was financially supported by Max Planck Society and National Key Research.

\section{Supplementary material}

Supplementary data associated with this article can be found, in the online version, at http://dx.doi.org/10.1016/j.nanoen.XXXX.XX.XXX

\section{Notes}

The authors declare no competing financial interest.

\section{References}

1. $\quad$ S. Chu, A. Majumdar, Nature 488 (2012) 294.

2. S. Pacala, R. Socolow, Science 305 (2004) 968.

3. $\quad$ N. S. Lewis, Science 315 (2007) 798.

4. D. Schmidt, M. D. Hager, U. S. Schubert, Adv. Energy Mater. 6 (2016) 1500369.

5. A. Paolella, C. Faure, G. Bertoni, S. Marras, A. Guerfi, A. Darwiche, P. Hovington, B. Commarieu, Z. Wang, M. Prato, M. Colombo, S. Monaco, W. Zhu, Z. Feng, A. Vijh, C. George, G. P. Demopoulos, M. Armand, K. Zaghib, Nat. Commun. 8 (2017) 14643.

6. $\quad$ P. Chen, G.-R. Li, T.-T. Li and X.-P. Gao, Adv. Sci., 6 (2019) 1900620.

7. $\quad$ N. F. Yan, G. R. Li, X. P. Gao, J. Mater. Chem. A 1 (2013) 7012.

8. $\quad$ S. L. Kim, H. T. Lin, C. Yu, Adv. Energy Mater. 6 (2016)1600546.

9. $\quad$ F. Podjaski, J. Kroger, B. V. Lotsch, Adv. Mater. 30 (2018) 1705477.

10. S. Ahmad, C. George, D. J. Beesley, J. J. Baumberg, M. De Volder, Nano Lett. 18 (2018) 1856.

11. Z. Tian, C. Li, J. Cai, L. Zhang, C. Lu, Y. Song, T. Jiang, J. Sun and S. Dou, Chem. Commun., 55 (2019) 1291.

12. Z. Yang, L. Li, Y. Luo, R. He, L. Qiu, H. Lin, H. Peng, J. Mater. Chem. A 1 (2013) 954.

13. J. Xu, Y. Chen, L. Dai, Nat. Commun. 6 (2015) 8103.

14. Y.-Y. Gui, F.-X. Ai, J.-F. Qian, Y.-L. Cao, G.-R. Li, X.-P. Gao, H.-X. Yang, J. Mater. Chem. A 6 (2018) 10627.

15. Q. Li, Y. Liu, S. Guo, H. Zhou, Nano Today 16 (2017) 46.

16. V. R. Stamenkovic, D. Strmcnik, P. P. Lopes, N. M. Markovic, Nat. Mater. 16 (2016) 57.

17. J. Xu, D. A. Lavan, Nat. Nanotechnol. 3 (2008) 666.

18. K. Xiao, L. Chen, R. Chen, T. Heil, S. D. C. Lemus, F. Fan, L. Wen, L. Jiang, M. Antonietti, Nat. Commun. 10 (2019) 74.

19. B. Hille, Ion channels of excitable membranes, Vol. 507, Sinauer Sunderland, MA, 2001.

20. K. Xiao, P. Giusto, L. Wen, L. Jiang, M. Antonietti, Angew. Chem. Int. Ed. 57 (2018) 10123. 
21. S. P. Surwade, S. N. Smirnov, I. V. Vlassiouk, R. R. Unocic, G. M. Veith, S. Dai, S. M. Mahurin, Nat. Nanotechnol. 10 (2015) 459.

22. Q. Liu, K. Xiao, L. Wen, H. Lu, Y. Liu, X.-Y. Kong, G. Xie, Z. Zhang, Z. Bo, L. Jiang, J. Am. Chem. Soc. 137 (2015)11976.

23. Q. Ruan, W. Luo, J. Xie, Y. Wang, X. Liu, Z. Bai, C. J. Carmalt and J. Tang, Angew. Chem. Int. Ed., 56 (2017) 8221.

24. M. Huang, Y.-L. Zhao, W. Xiong, S. V. Kershaw, Y. Yu, W. Li, T. Dudka and R.-Q. Zhang, Appl. Catal. B-Environ., 237 (2018) 783.

25. Y. Zhang, A. Thomas, M. Antonietti and X. Wang, J. Am. Chem. Soc., 131 (2009) 50.

26. J. Liu, H. Q. Wang, Z. P. Chen, H. Moehwald, S. Fiechter, R. van de Krol, L. P. Wen, L. Jiang and M. Antonietti, Adv. Mater., 27 (2015) 712.

27. W. J. Ong, L. L. Tan, Y. H. Ng, S. T. Yong and S. P. Chai, Chem. Rev., 116 (2016) 7159.

28. H. Arazoe, D. Miyajima, K. Akaike, F. Araoka, E. Sato, T. Hikima, M. Kawamoto and T. Aida, Nat. Mater., 15 (2016) 1084.

29. L. Lin, H. Ou, Y. Zhang, X. Wang, ACS Catalysis 6 (2016) 3921.

30. L. L. Zhang, X. S. Zhao, Chem. Soc. Rev. 38 (2009) 2520.

31. H. Ohshima, S. Ohki, Biophys. J. 47 (1985) 673.

32. P. Sistat, A. Kozmai, N. Pismenskaya, C. Larchet, G. Pourcelly, V. J. E. A. Nikonenko, Electrochimica Acta 53 (2008) 6380.

33. A. A. Moya, J. Phys. Chem. C 118 (2014) 2539.

34. X. Li, C. Shen, Q. Wang, C. M. Luk, B. Li, J. Yin, S. P. Lau, W. J. N. E. Guo, Nano Energy 32 (2017) 125.

35. W. Sparreboom, A. van den Berg, J. C. T. Eijkel, Nat. Nanotechnol. 4 (2009) 713.

36. D. C. Grahame, Chem. Rev. 41 (1947) 441.

37. G. Xue, Y. Xu, T. Ding, J. Li, J. Yin, W. Fei, Y. Cao, J. Yu, L. Yuan, L. Gong, J. Chen, S. Deng, J. Zhou, W. Guo, Nat. Nanotechnol. 12 (2017) 317.

38. X. Zhu, J. Hao, B. Bao, Y. Zhou, H. Zhang, J. Pang, Z. Jiang, L. Jiang, Sci. Adv. 4 (2018) 1665.

39. D. Schmidt, M. D. Hager and U. S. Schubert, Adv. Energy Mater., 6 (2016) 1500369.

40. C. Li, S. Cong, Z. Tian, Y. Song, L. Yu, C. Lu, Y. Shao, J. Li, G. Zou, M. H. Rümmeli, S. Dou, J. Sun and Z. Liu, Nano Energy, 60 (2019) 247.

41. M. Macha, S. Marion, V. V. R. Nandigana and A. Radenovic, Nat. Rev. Mater., 4 (2019) 588.

42. K. Xiao, L. Jiang, M. Antonietti. Joule, 2019, DOI: 10.1016/j.joule.2019.09.005.

43. M. Graf, M. Lihter, D. Unuchek, A. Sarathy, J.-P. Leburton, A. Kis and A. Radenovic, Joule, 3 (2019) 1549.

44. M. Lozada-Hidalgo, S. Zhang, S. Hu, V. G. Kravets, F. J. Rodriguez, A. Berdyugin, A. Grigorenko and A. K. Geim, Nat. Nanotechnol., 2018, 13, 300.

45. Z. Zhang, X.-Y. Kong, G. Xie, P. Li, K. Xiao, L. Wen and L. Jiang, Sci. Adv., 2 (2016) e1600689. 